\title{
Hybrid Pyrrole-Imidazole Alkaloids from the Sponge Agelas sceptrum
}

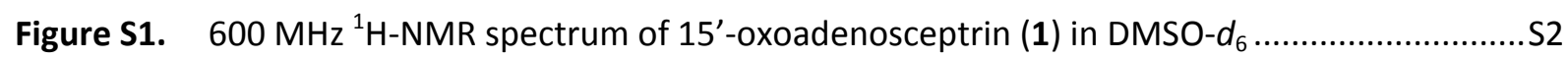

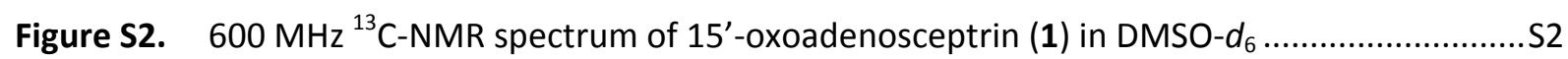

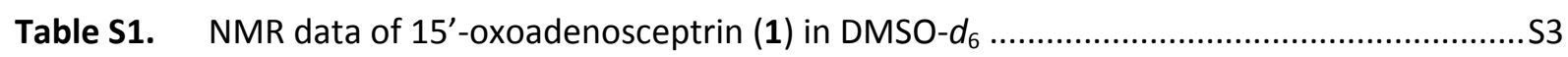

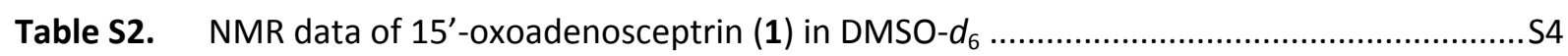

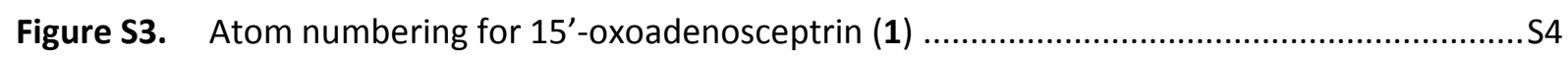

Figure S4. Key COSY and HMBC correlations for $15^{\prime}$-oxoadenosceptrin (1) ....................................S5

Figure S5. $600 \mathrm{MHz}{ }^{1} \mathrm{H}-\mathrm{NMR}$ spectrum of decarboxyagelamadin C (2) in DMSO-d $d_{6} \ldots \ldots \ldots \ldots \ldots \ldots \ldots . . . . . . . . . . . . . .66$

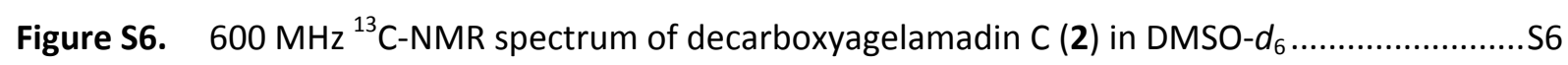

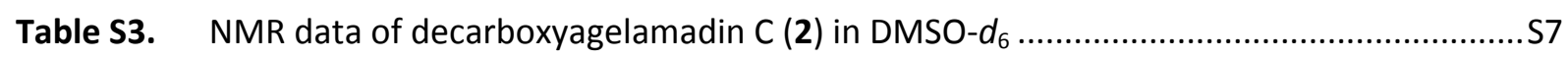

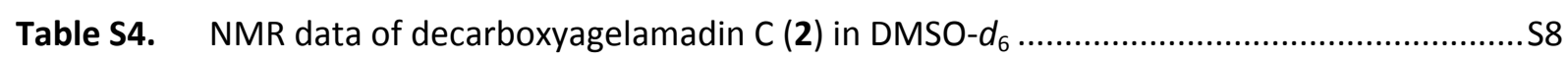

Figure S7. Atom numbering for decarboxyagelamadin C (2) .................................................. 8

Figure S8. Key COSY and ${ }^{1} \mathrm{H},{ }^{13} \mathrm{C}-\mathrm{HMBC}$ correlations for decarboxyagelamadin $\mathrm{C}$ (2)........................ 9

Figure S9. CD spectra of $15^{\prime}$-oxoadenosceptrin (1) and decarboxyagelamadin C (2) ....................S10

Figure S10. UV spectra of 15'-oxoadenosceptrin (1) and decarboxyagelamadin C (2) ....................S11

Figure S11. $600 \mathrm{MHz}{ }^{1} \mathrm{H}-\mathrm{NMR}$ spectrum of 8-oxo-9-methyladenine (6) in DMSO- $d_{6} \ldots \ldots \ldots \ldots \ldots \ldots \ldots . . . . . . . . . . .212$

Figure S12. $600 \mathrm{MHz}{ }^{13} \mathrm{C}-\mathrm{NMR}$ spectrum of 8-oxo-9-methyladenine (6) in DMSO-d $d_{6} \ldots \ldots \ldots \ldots \ldots \ldots \ldots . . . . . . . . . . . .212$

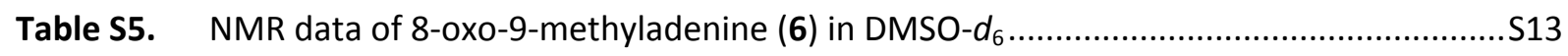

Figure S13. Atom numbering for 8-oxo-9-methyladenine (6) ................................................. 13

Figure S14. Key COSY and ${ }^{1} \mathrm{H},{ }^{13} \mathrm{C}-\mathrm{HMBC}$ correlations for 8-oxo-9-methyladenine (6) ......................S13

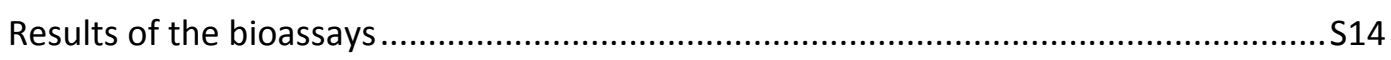

Table S6. MIC values for compounds 1-5 tested against bacteria strains ....................................S14

Table S7. Results for compounds 1-5 tested against different cancer cell lines............................S14

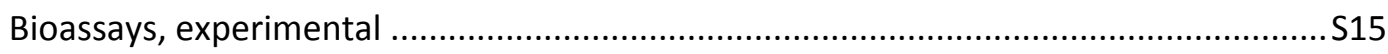




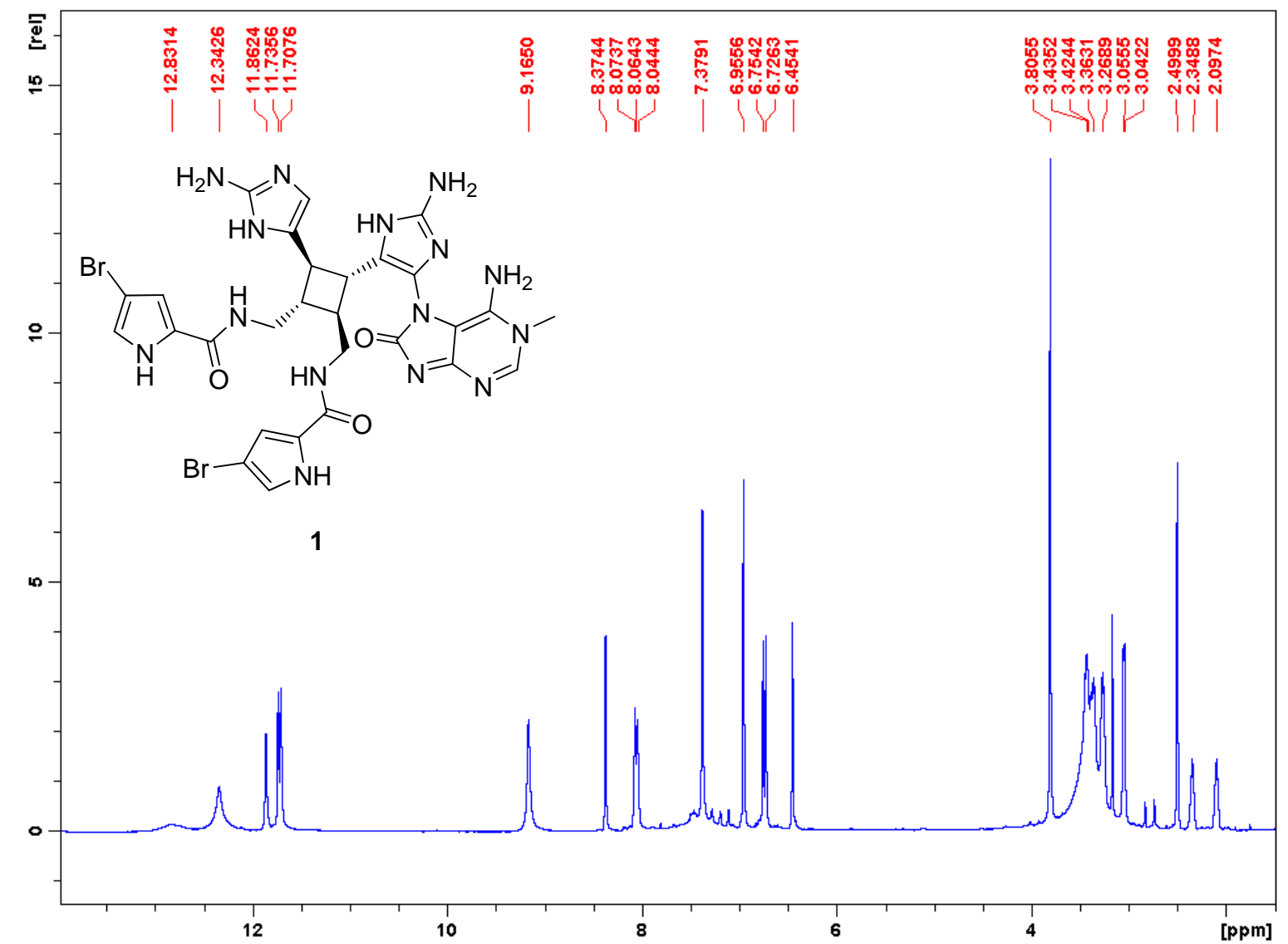

Figure S1. $600 \mathrm{MHz}{ }^{1} \mathrm{H}-\mathrm{NMR}$ spectrum of $15^{\prime}$-oxoadenosceptrin (1) in DMSO- $d_{6}$.

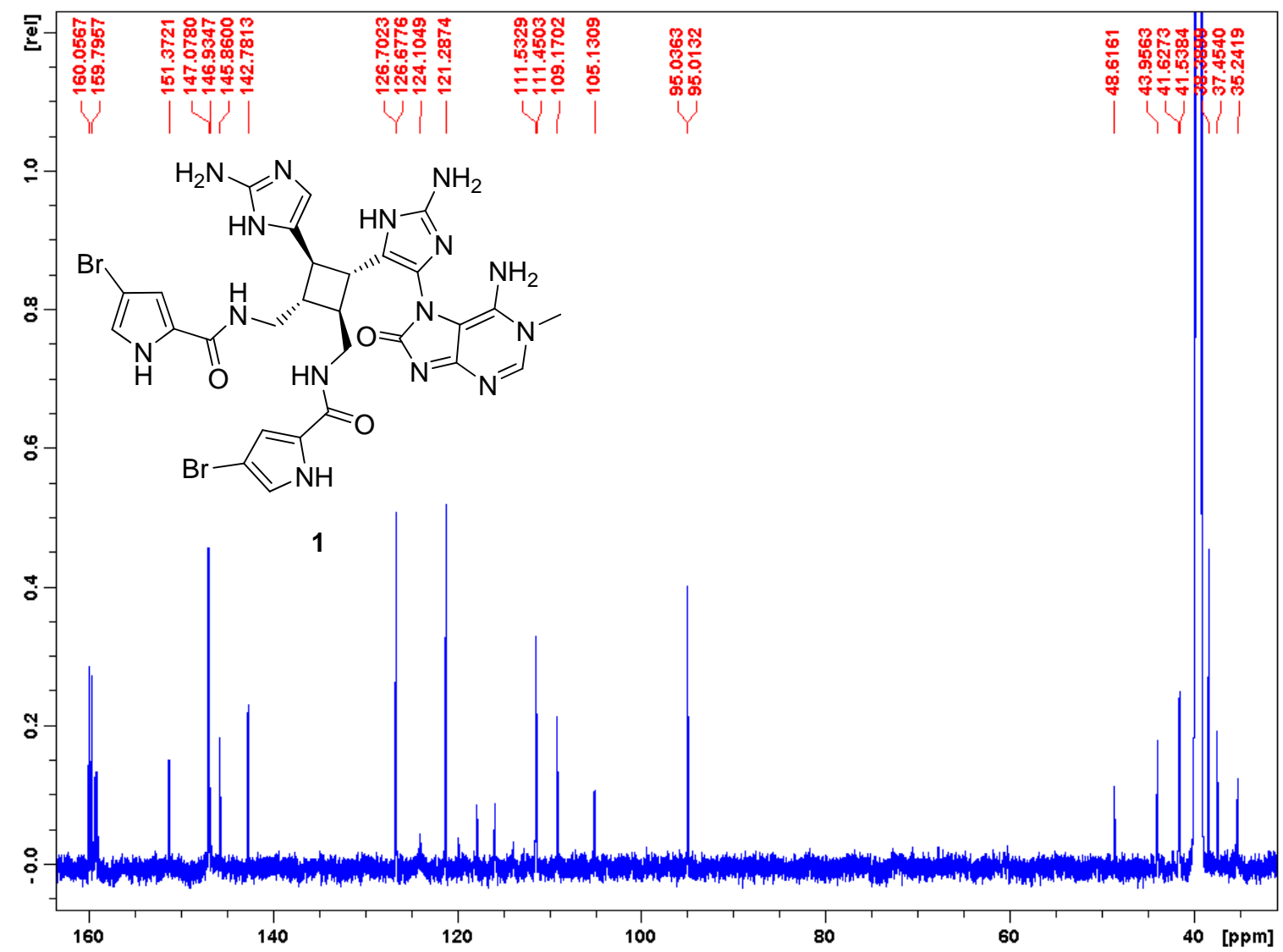

Figure S2. $600 \mathrm{MHz}{ }^{13} \mathrm{C}-\mathrm{NMR}$ spectrum of $15^{\prime}$-oxoadenosceptrin (1) in DMSO- $d_{6}$. 
Table S1. NMR data of $15^{\prime}$-oxoadenosceptrin (1) in DMSO- $d_{6}$.

\begin{tabular}{|c|c|c|c|c|c|}
\hline Pos. & $\delta\left({ }^{1} \mathrm{H}\right)$ & $\delta\left({ }^{13} \mathrm{C}\right)$ & $\delta\left({ }^{15} \mathrm{~N}\right)$ & ${ }^{1} \mathrm{H},{ }^{1} \mathrm{H}-\mathrm{COSY}$ & ${ }^{1} \mathrm{H},{ }^{13} \mathrm{C}-\mathrm{HMBC}$ \\
\hline $1 / 1^{\prime}$ & $11.72(2 \mathrm{H}, \mathrm{brs})$ & - & 161 & $4 / 4^{\prime}$ & $2 / 2^{\prime}, 3 / 3^{\prime}, 4 / 4^{\prime}, 5 / 5^{\prime}$ \\
\hline $2 / 2^{\prime}$ & $6.96(2 \mathrm{H}, \mathrm{s})$ & 121.3 & - & $1 / 1^{\prime}$ & $3 / 3^{\prime}, 4 / 4^{\prime}, 5 / 5^{\prime}, 6,6^{\prime}$ \\
\hline $3 / 3^{\prime}$ & - & 95.0 & - & - & - \\
\hline $4 / 4^{\prime}$ & $6.74(2 \mathrm{H}, \mathrm{s})$ & 111.5 & - & $1 / 1^{\prime}$ & $2 / 2^{\prime}, 5 / 5^{\prime}, 6 / 6^{\prime}$ \\
\hline $5 / 5^{\prime} / 11^{\prime}$ & - & 126.7 & - & - & - \\
\hline 6 & - & 159.8 & - & - & - \\
\hline 7 & $8.07(1 \mathrm{H}, \mathrm{brt})$ & - & 106 & $8 a, 8 b$ & $5 / 5^{\prime}, 6,8$ \\
\hline \multirow[t]{2}{*}{8} & $3.27(1 \mathrm{H}, \mathrm{m})$ & 41.5 & - & 9,7 & $6,9,9^{\prime}, 10$ \\
\hline & $3.36(1 \mathrm{H}, \mathrm{m})$ & & & & \\
\hline 9 & $2.35(1 \mathrm{H}, \mathrm{m})$ & 41.5 & - & $8,9^{\prime}, 10 / 10^{\prime}$ & $9^{\prime}, 10,10^{\prime}, 11,11^{\prime}$ \\
\hline \multirow[t]{2}{*}{$10 / 10^{\prime}$} & $3.04(2 \mathrm{H}, \mathrm{m})$ & 35.2 & - & $9,9^{\prime}$ & $8,8^{\prime}, 9,11,11^{\prime}, 15^{\prime}$ \\
\hline & & 37.5 & & & \\
\hline 11 & - & 124.1 & - & - & - \\
\hline 12 & $12.34(1 \mathrm{H}, \mathrm{brs})$ & - & 138 & - & - \\
\hline $13 / 13^{\prime} / 15$ & - & 147.1 & - & - & - \\
\hline 14 & - & - & n.d. & - & - \\
\hline 16 & n.d. & - & n.d. & - & - \\
\hline $6^{\prime}$ & - & 160.1 & - & - & - \\
\hline $7^{\prime}$ & $8.04(1 \mathrm{H}, \mathrm{brt})$ & - & 106 & $8^{\prime} a, 8^{\prime} b$ & $5 / 5^{\prime}, 6^{\prime}, 8^{\prime}$ \\
\hline \multirow[t]{2}{*}{$8^{\prime}$} & $3.27(1 \mathrm{H}, \mathrm{m})$ & 41.5 & - & $9^{\prime}, 11^{\prime}$ & $6^{\prime}, 9,9^{\prime}, 10^{\prime}$ \\
\hline & $3.44(1 \mathrm{H}, \mathrm{m})$ & & & & \\
\hline $9^{\prime}$ & $2.10(1 \mathrm{H}, \mathrm{m})$ & 44.0 & - & $8^{\prime}, 9,10 / 10^{\prime}$ & $8 / 8^{\prime} / 9,10^{\prime}, 11^{\prime}$ \\
\hline $12^{\prime}$ & - & - & 137 & - & - \\
\hline $14^{\prime}$ & $11.86(1 \mathrm{H}, \mathrm{brs})$ & - & 134 & $15^{\prime}$ & $5 / 5^{\prime} / 11^{\prime}, 13 / 13^{\prime} / 15,15^{\prime}$ \\
\hline $15^{\prime}$ & $6.45(1 \mathrm{H}, \mathrm{s})$ & 109.2 & - & - & $\begin{array}{l}5 / 5^{\prime} / 11^{\prime}, 9^{\prime}, 10 / 10^{\prime} \\
13 / 13^{\prime} / 15\end{array}$ \\
\hline $16^{\prime}$ & $7.38(2 \mathrm{H}, \mathrm{brs})$ & - & 57 & - & - \\
\hline $1^{\prime \prime}$ & - & - & 157 & - & - \\
\hline $2^{\prime \prime}$ & $8.37(1 \mathrm{H}, \mathrm{s})$ & 146.9 & - & - & $4^{\prime \prime}, 5^{\prime \prime}, 6^{\prime \prime}, 10^{\prime \prime}$ \\
\hline $3^{\prime \prime}$ & - & - & 225 & - & - \\
\hline $4^{\prime \prime}$ & - & 145.9 & - & - & - \\
\hline $5^{\prime \prime}$ & - & 105.1 & - & - & - \\
\hline $6^{\prime \prime}$ & - & 142.8 & - & - & - \\
\hline $7^{\prime \prime}$ & - & - & n.d. & - & - \\
\hline $8^{\prime \prime}$ & - & 151.4 & - & - & - \\
\hline $9^{\prime \prime}$ & - & - & n.d. & - & - \\
\hline $10^{\prime \prime}$ & $3.81(3 \mathrm{H}, \mathrm{s})$ & 38.4 & - & - & $2^{\prime \prime}, 6^{\prime \prime}$ \\
\hline $11^{\prime \prime}$ & $9.16(2 \mathrm{H}, \mathrm{brs})$ & - & 87 & - & - \\
\hline
\end{tabular}

n.d.: not detected; $X / Y$ means that both atoms have the same chemical shift 
Table S2. NMR data of $15^{\prime}$-oxoadenosceptrin (1) in DMSO- $d_{6}$.

\begin{tabular}{lllll}
\hline Pos. & $\delta\left({ }^{1} \mathrm{H}\right)$ & ${ }^{1} \mathbf{H}^{15}{ }^{15} \mathrm{~N}-\mathrm{HMBC}$ & $\mathbf{1 , 1 - A D E Q U A T E}$ & ${ }^{1} \mathrm{H}^{1}{ }^{1} \mathrm{H}-\mathrm{ROESY}$ \\
\hline $1 / 1^{\prime}$ & $11.72(1 \mathrm{H}, \mathrm{brs})$ & - & - & $2 / 2^{\prime}, 7 / 7^{\prime}$ \\
$2 / 2^{\prime}$ & $6.96(1 \mathrm{H}, \mathrm{s})$ & $1 / 1^{\prime}$ & $3 / 3^{\prime}$ & $1 / 1^{\prime}$ \\
$4 / 4^{\prime}$ & $6.74(1 \mathrm{H}, \mathrm{s})$ & $1 / 1^{\prime}$ & $3 / 3^{\prime}, 5 / 5^{\prime}$ & $7 / 7^{\prime}$ \\
7 & $8.07(1 \mathrm{H}, \mathrm{brt})$ & - & - & $4 / 4^{\prime}, 8 / 8^{\prime}, 9^{\prime}, 9,10 / 10^{\prime}$ \\
8 & $3.27(1 \mathrm{H}, \mathrm{m})$ & $7 / 7^{\prime}$ & - & $7 / 7^{\prime}, 8 \mathrm{a}, 8^{\prime} \mathrm{a}, 9,9^{\prime}$ \\
& $3.36(1 \mathrm{H}, \mathrm{m})$ & & & $7 / 7^{\prime}, 8 \mathrm{a}, 8^{\prime} \mathrm{a}, 9,9^{\prime}$ \\
9 & $2.35(1 \mathrm{H}, \mathrm{m})$ & - & $9^{\prime}$ & $7 / 7^{\prime}, 8^{\prime} \mathrm{ab}, 8 \mathrm{ab}, 10 / 10^{\prime}$ \\
$10 / 10^{\prime}$ & $3.04(1 \mathrm{H}, \mathrm{m})$ & $12,12^{\prime}$ & $9^{\prime}, 5 / 5^{\prime} / 11^{\prime}$ & $7 / 7^{\prime}, 8^{\prime} \mathrm{ab}, 8 \mathrm{ab}, 9,9^{\prime}, 15^{\prime}$ \\
12 & $12.34(1 \mathrm{H}, \mathrm{brs})$ & - & - & - \\
$7^{\prime}$ & $8.04(1 \mathrm{H}, \mathrm{brt})$ & - & - & $4 / 4^{\prime}, 8 / 8^{\prime}, 9^{\prime}, 9,10 / 10^{\prime}$ \\
$8^{\prime}$ & $3.27(1 \mathrm{H}, \mathrm{m})$ & $7 / 7^{\prime}$ & $9^{\prime}$ & $7 / 7^{\prime}, 8 \mathrm{a}, 8^{\prime} \mathrm{a}, 9,9$, \\
& $3.44(1 \mathrm{H}, \mathrm{m})$ & & & $7 / 7^{\prime}, 8 \mathrm{a}, 8^{\prime} \mathrm{a}, 9,99^{\prime}$ \\
$9^{\prime}$ & $2.10(1 \mathrm{H}, \mathrm{m})$ & - & $8 / 8^{\prime} / 9,10^{\prime}$ & $8^{\prime} \mathrm{ab}, 8 \mathrm{ab}, 7 / 7^{\prime}, 10 / 10^{\prime}$ \\
$14^{\prime}$ & $11.86(1 \mathrm{H}, \mathrm{brs})$ & - & - & $15^{\prime}$ \\
$15^{\prime}$ & $6.70(1 \mathrm{H}, \mathrm{s})$ & $12^{\prime}, 14^{\prime}$ & - & $9^{\prime}, 9,10 / 10^{\prime}, 14^{\prime}$ \\
$16^{\prime}$ & $7.38(2 \mathrm{H}, \mathrm{brs})$ & $12^{\prime}, 14^{\prime}$ & - & - \\
$2^{\prime \prime}$ & $8.37(1 \mathrm{H}, \mathrm{s})$ & $1^{\prime \prime}, 3^{\prime \prime}$ & - & $10^{\prime \prime}$ \\
$10^{\prime \prime}$ & $3.81(3 \mathrm{H}, \mathrm{s})$ & $1^{\prime \prime}, 11^{\prime \prime}$ & - & $2^{\prime \prime}, 11^{\prime \prime}$ \\
\hline
\end{tabular}
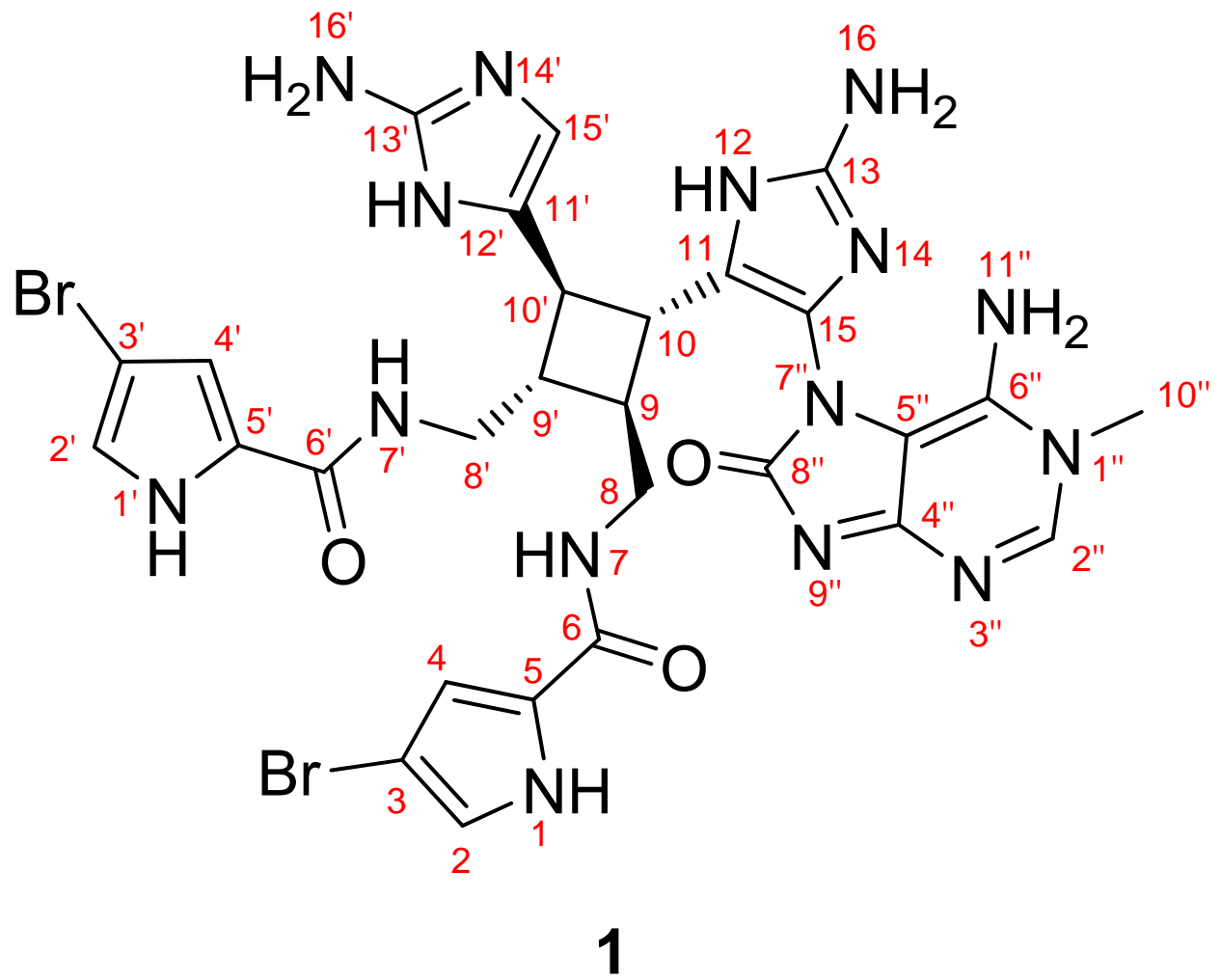

Figure S3. Atom numbering for 15'-oxoadenosceptrin (1). 


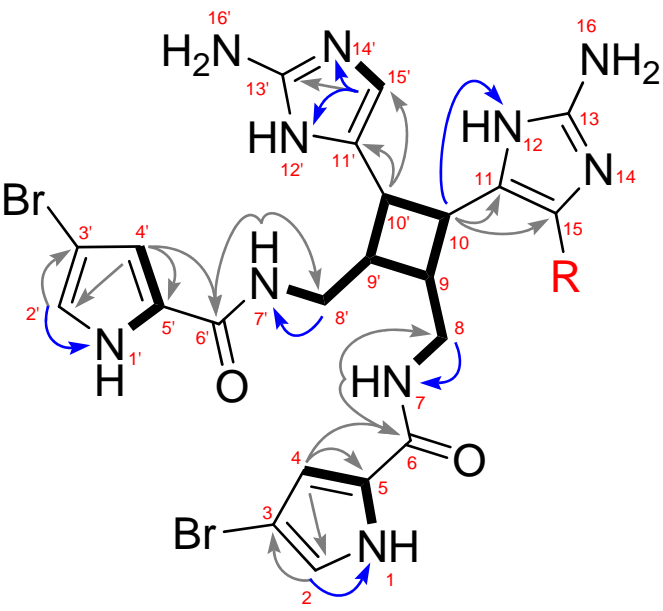

sceptrin part

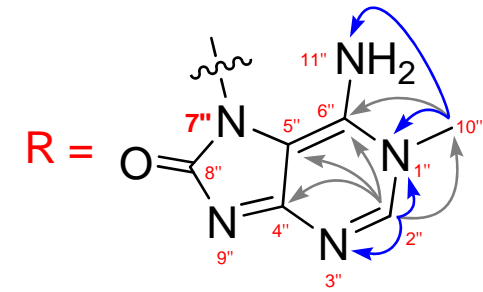

or

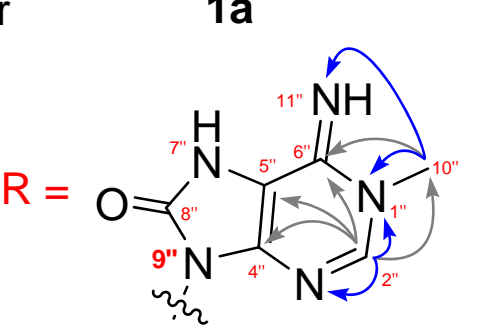

$1 \mathbf{b}$

adenine part

1

Figure S4. Key COSY (bold line), ${ }^{1} \mathrm{H},{ }^{13} \mathrm{C}-\mathrm{HMBC}$ (gray arrows), and ${ }^{1} \mathrm{H},{ }^{15} \mathrm{~N}-\mathrm{HMBC}$ (blue arrows) correlations for 15'-oxoadenosceptrin (1). 


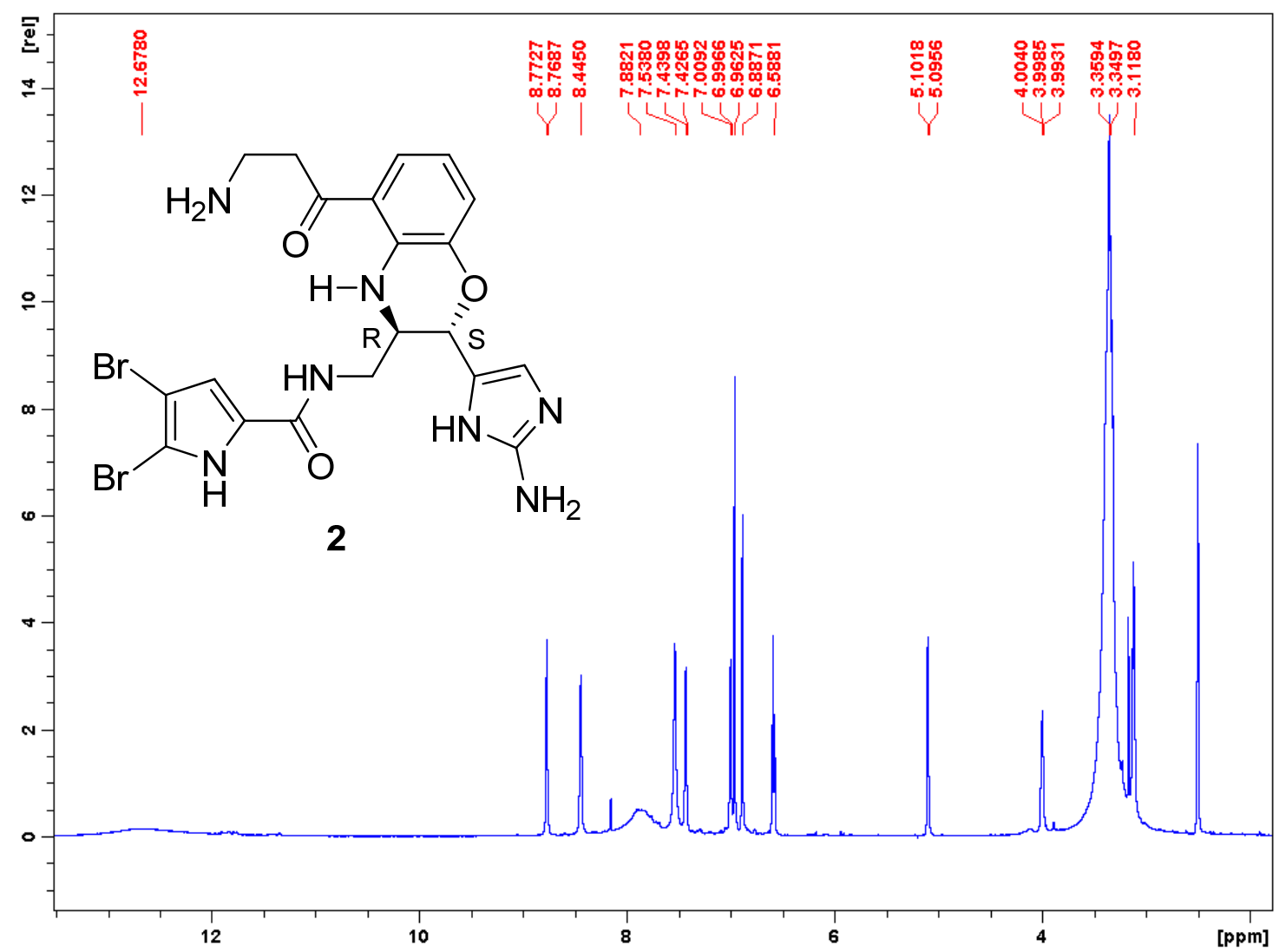

Figure $55.600 \mathrm{MHz}{ }^{1} \mathrm{H}-\mathrm{NMR}$ spectrum of decarboxyagelamadin $\mathrm{C}(2)$ in DMSO- $d_{6}$.

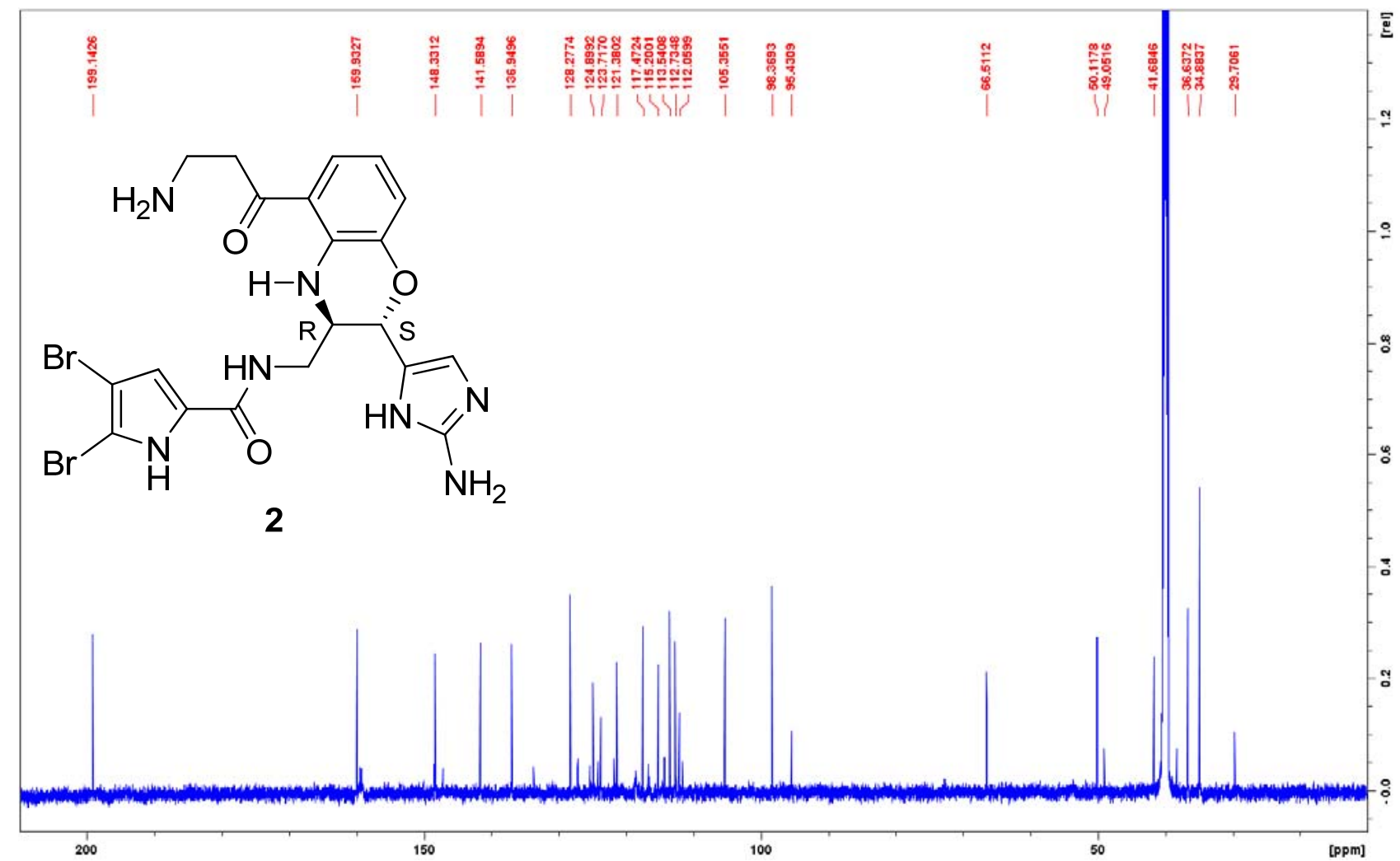

Figure $56.600 \mathrm{MHz}{ }^{13} \mathrm{C}-\mathrm{NMR}$ spectrum of decarboxyagelamadin C (2) in DMSO- $d_{6}$. 
Table S3. NMR data of decarboxyagelamadin C (2) in DMSO- $d_{6}$.

\begin{tabular}{|c|c|c|c|c|c|}
\hline Pos. & $\delta\left({ }^{1} \mathrm{H}\right)$ & $\delta\left({ }^{13} \mathrm{C}\right)$ & $\delta\left({ }^{15} \mathrm{~N}\right)$ & ${ }^{1} \mathrm{H},{ }^{1} \mathrm{H}-\mathrm{COS} Y$ & ${ }^{1} \mathrm{H},{ }^{13} \mathrm{C}-\mathrm{HMBC}$ \\
\hline 1 & $12.68(1 \mathrm{H}, \mathrm{brs})$ & - & 166 & - & - \\
\hline 2 & - & 104.9 & - & - & - \\
\hline 3 & - & 97.9 & - & - & - \\
\hline 4 & $6.96(1 \mathrm{H}, \mathrm{s})$ & 113.1 & - & - & $2,3,5,6$ \\
\hline 5 & - & 127.8 & - & - & - \\
\hline 6 & - & 159.5 & - & - & - \\
\hline 7 & $8.45(1 \mathrm{H}, \mathrm{brt}, 6.0)$ & - & 101 & 8 & 6,8 \\
\hline 8 & $3.36(2 \mathrm{H}, \mathrm{m})$ & 41.2 & - & 7,9 & $6,9,10$ \\
\hline 9 & $3.99(1 \mathrm{H}, \mathrm{m})$ & 49.7 & - & $8,10,11^{\prime}$ & 6 \\
\hline 10 & $5.10(1 \mathrm{H}, \mathrm{d}, 3.7)$ & 66.3 & - & 9 & $2^{\prime}, 8,9,11,15$ \\
\hline 11 & - & 123.7 & - & - & - \\
\hline $12 / 14$ & - & - & $136(2 N)$ & - & - \\
\hline 13 & - & 147.9 & - & - & - \\
\hline 15 & $6.89(1 \mathrm{H}, \mathrm{s})$ & 112.2 & - & - & 11,13 \\
\hline 16 & $7.56(2 \mathrm{H}, \mathrm{brs})$ & - & 58 & - & - \\
\hline $1^{\prime}$ & - & 136.5 & - & - & - \\
\hline $2^{\prime}$ & - & 141.2 & - & - & - \\
\hline $3^{\prime}$ & $6.99(1 \mathrm{H}, \mathrm{d}, 7.7)$ & 120.9 & - & $4^{\prime}$ & $1^{\prime}, 2^{\prime}, 5^{\prime}$ \\
\hline $4^{\prime}$ & $6.59(1 \mathrm{H}, \mathrm{t}, 8.1)$ & 114.7 & - & $3^{\prime}, 5^{\prime}$ & $2^{\prime}, 6^{\prime}$ \\
\hline $5^{\prime}$ & $7.43(1 \mathrm{H}, \mathrm{d}, 7.7)$ & 124.4 & - & $4^{\prime}$ & $1^{\prime}, 2^{\prime}, 3^{\prime}, 6^{\prime}, 7^{\prime}$ \\
\hline $6^{\prime}$ & - & 117.0 & - & - & - \\
\hline $7^{\prime}$ & - & 198.7 & - & - & - \\
\hline $8^{\prime}$ & $3.32(2 \mathrm{H}, \mathrm{m})$ & 36.2 & - & $9^{\prime}$ & $7^{\prime}, 9^{\prime}$ \\
\hline $9^{\prime}$ & $3.12(2 \mathrm{H}, \mathrm{m})$ & 34.4 & - & $8^{\prime}$ & $7^{\prime}, 8^{\prime}$ \\
\hline $10^{\prime}$ & n.d. & - & 32 & - & - \\
\hline $11^{\prime}$ & $8.77(1 \mathrm{H}, \mathrm{brs})$ & - & 70 & 9 & $2^{\prime}, 6^{\prime}, 9,10$ \\
\hline
\end{tabular}


Table S4. NMR data of decarboxyagelamadin C (2) in DMSO- $d_{6}$.

\begin{tabular}{lllll}
\hline Pos. & $\delta\left({ }^{1} \mathbf{H}\right)$ & ${ }^{1} \mathbf{H}^{15} \mathbf{N}-$ HMBC & 1,1-ADEQUATE & ${ }^{1} \mathbf{H}^{1}{ }^{1} \mathbf{H}-$ ROESY \\
\hline 1 & $12.68(1 \mathrm{H}, \mathrm{brs})$ & - & - & - \\
4 & $6.96(1 \mathrm{H}, \mathrm{s})$ & 1 & 3,5 & 7 \\
7 & $8.45(1 \mathrm{H}, \mathrm{brt}, 6.0)$ & - & - & $4,8,9,10,11^{\prime}$ \\
8 & $3.36(2 \mathrm{H}, \mathrm{m})$ & $7,11^{\prime}$ & 9 & $7,9,10,11^{\prime}$ \\
9 & $3.99(1 \mathrm{H}, \mathrm{m})$ & - & 8,10 & $7,8,10,11^{\prime}, 15$ \\
10 & $5.10(1 \mathrm{H}, \mathrm{d}, 3.7)$ & $11^{\prime}, 12$ & 9,11 & $7,8,9,15$ \\
15 & $6.89(1 \mathrm{H}, \mathrm{s})$ & $12 / 14$ & - & 9,10 \\
16 & $7.56(2 \mathrm{H}, \mathrm{brs})$ & $12 / 14$ & - & - \\
$3^{\prime}$ & $6.99(1 \mathrm{H}, \mathrm{d}, 7.7)$ & - & $4^{\prime}$ & $4^{\prime}$ \\
$4^{\prime}$ & $6.59(1 \mathrm{H}, \mathrm{t}, 8.05)$ & - & $5^{\prime}$ & $3^{\prime}, 5^{\prime}$ \\
$5^{\prime}$ & $7.43(1 \mathrm{H}, \mathrm{d}, 7.7)$ & - & $4^{\prime}$ & $4^{\prime}, 8^{\prime}$ \\
$8^{\prime}$ & $3.32(2 \mathrm{H}, \mathrm{m})$ & $10^{\prime}$ & $7^{\prime}, 9^{\prime}$ & $5^{\prime}, 9^{\prime}$ \\
$9^{\prime}$ & $3.12(2 \mathrm{H}, \mathrm{m})$ & - & $8^{\prime}$ & $8^{\prime}$ \\
$11^{\prime}$ & $8.77(1 \mathrm{H}, \mathrm{brs})$ & - & - & $7,8^{\prime}, 9,10,15$ \\
\hline
\end{tabular}

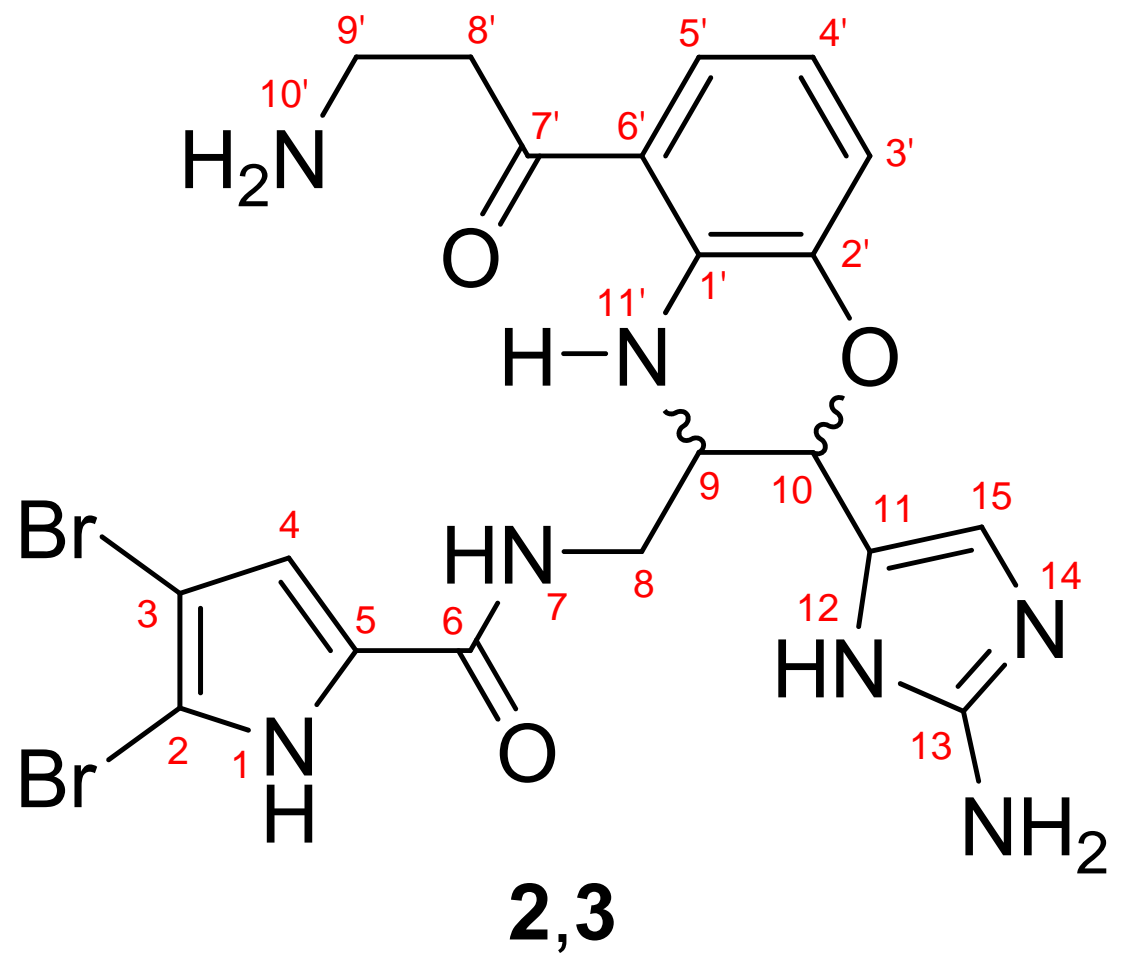

Figure S7. Atom numbering for decarboxyagelamadin C (2) and decarboxyagelamadin E. 


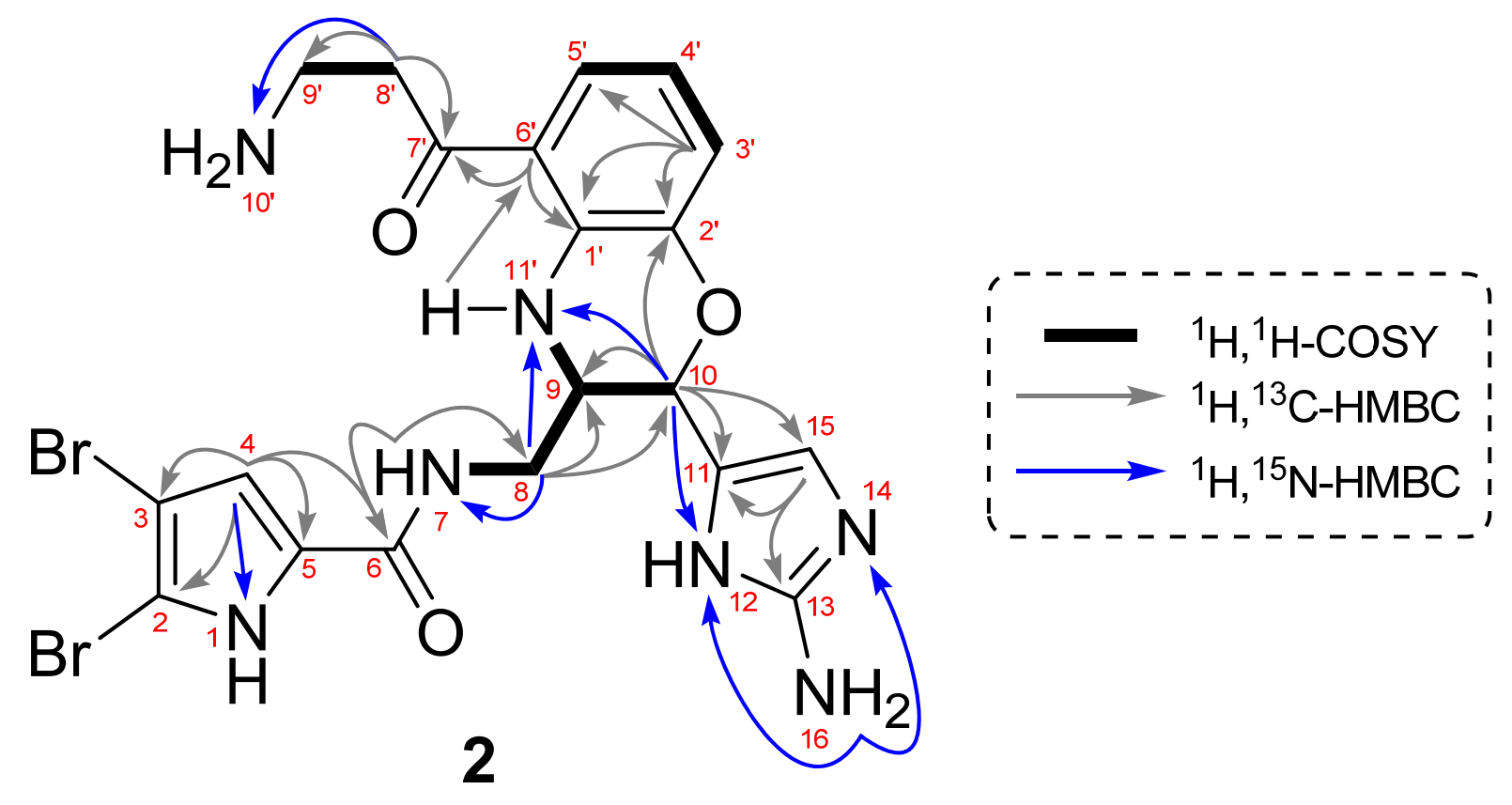

Figure S8. Key COSY (bold line), ${ }^{1} \mathrm{H},{ }^{13} \mathrm{C}-\mathrm{HMBC}$ (gray arrows), and ${ }^{1} \mathrm{H}^{15} \mathrm{~N}-\mathrm{HMBC}$ (blue arrows) correlations for decarboxyagelamadin C (2). 


\section{Compound 1 and other known compounds from}

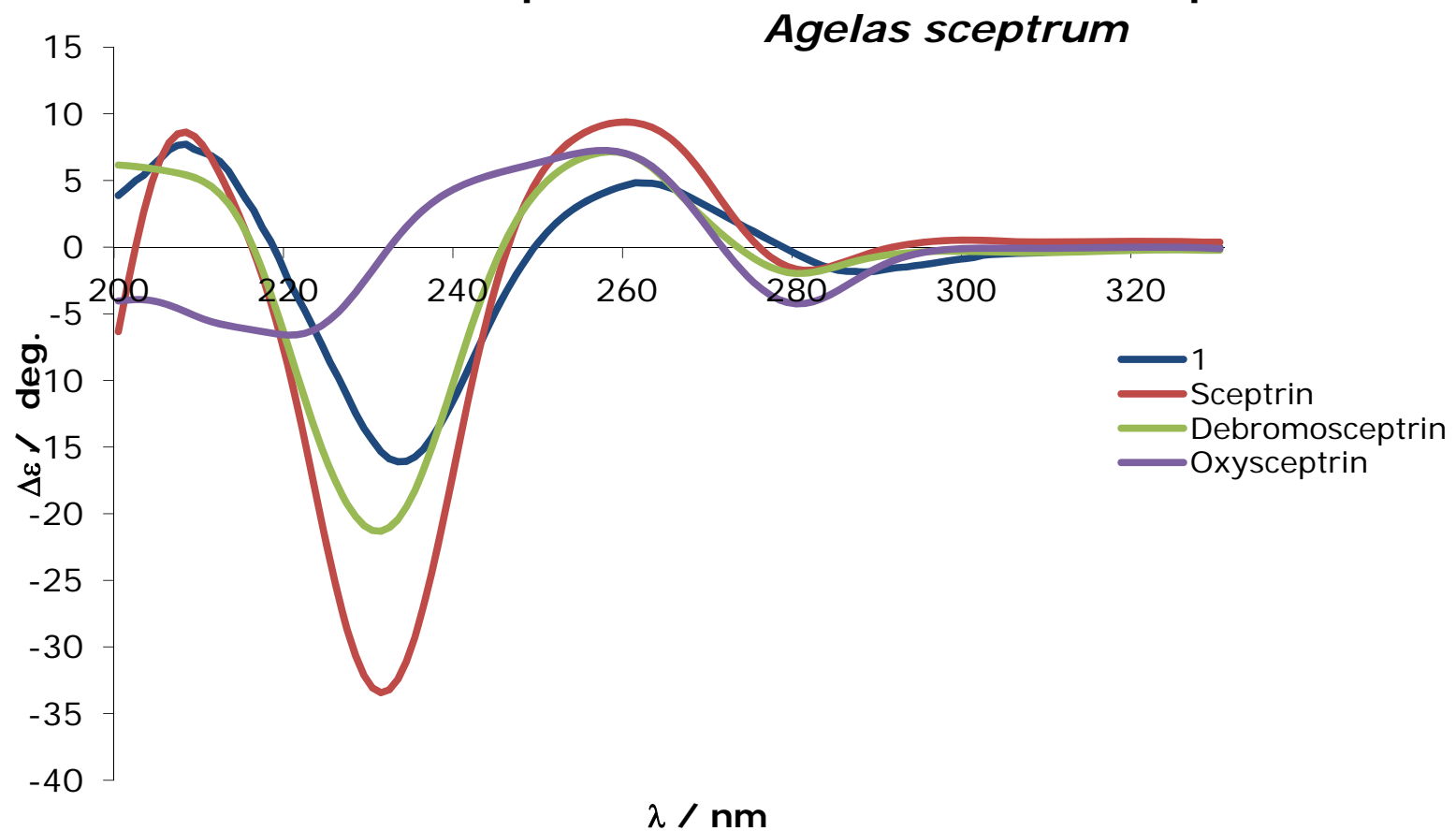

$\lambda / \mathbf{n m}$

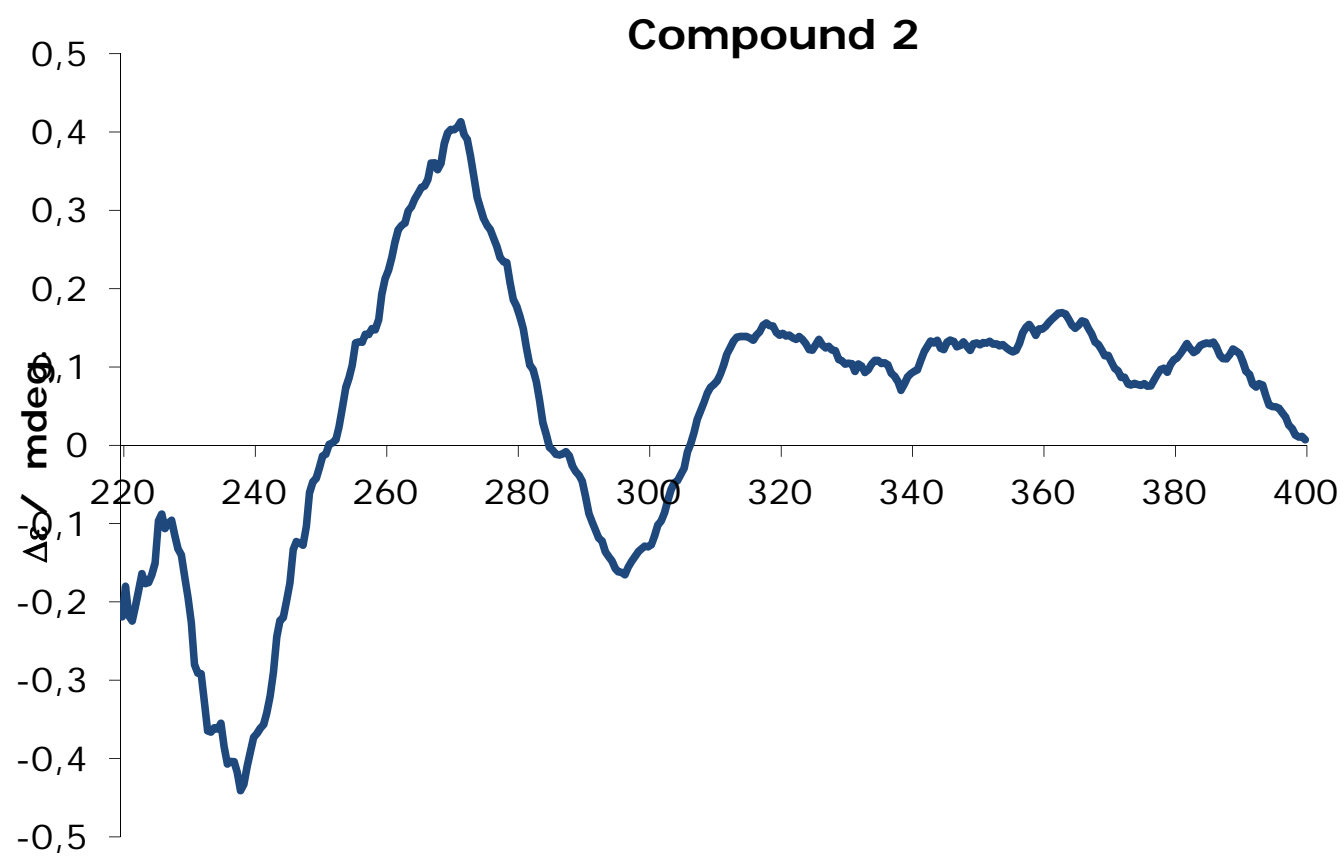

$\lambda / \mathbf{n m}$

Figure S9. CD spectra of 15'-oxoadenosceptrin (1) and decarboxyagelamadin C (2). 

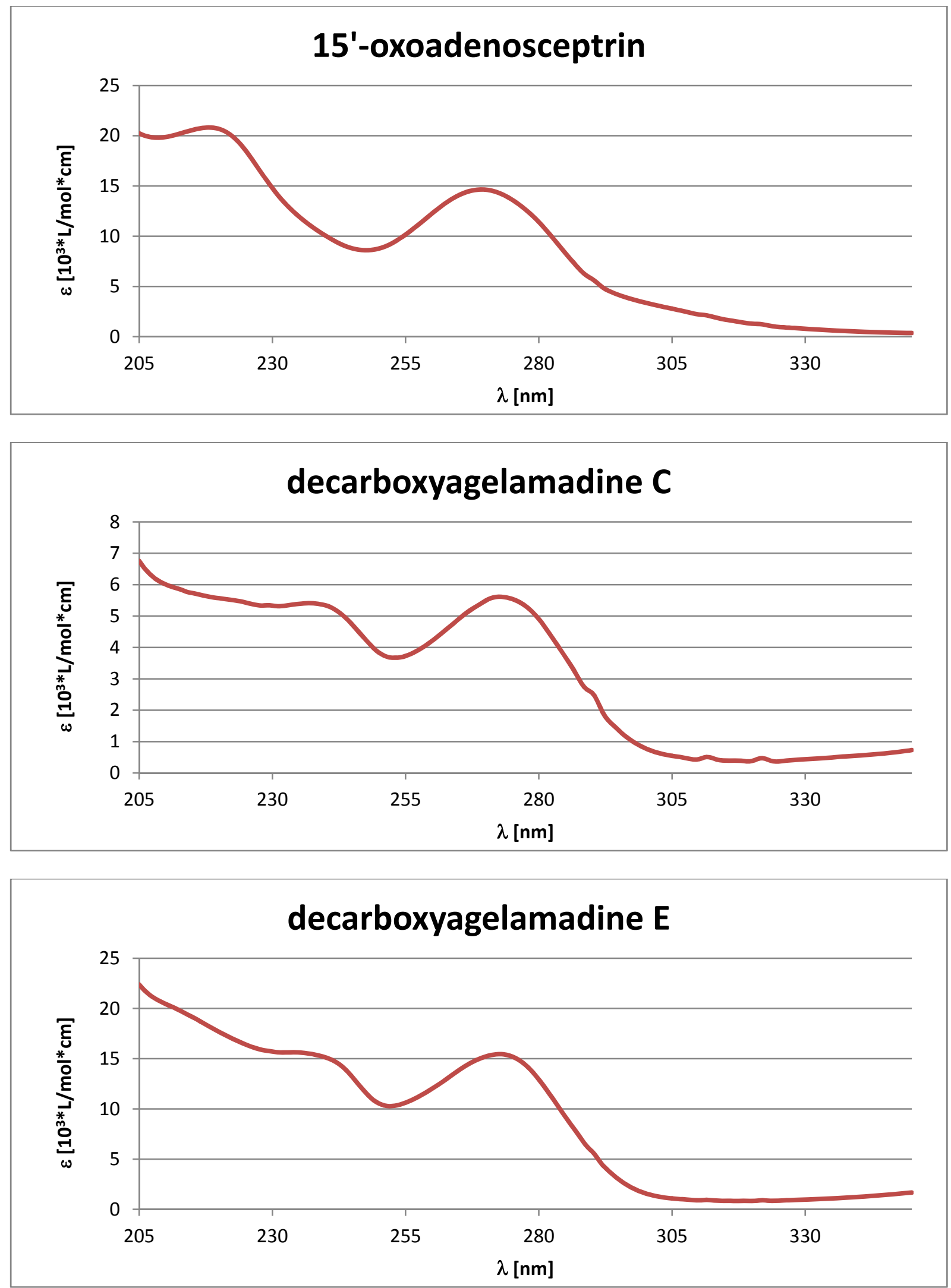

Figure S10. UV spectra of 15'-oxoadenosceptrin (1), decarboxyagelamadin C (2), and decarboxyagelamadin $\mathrm{E}$. 


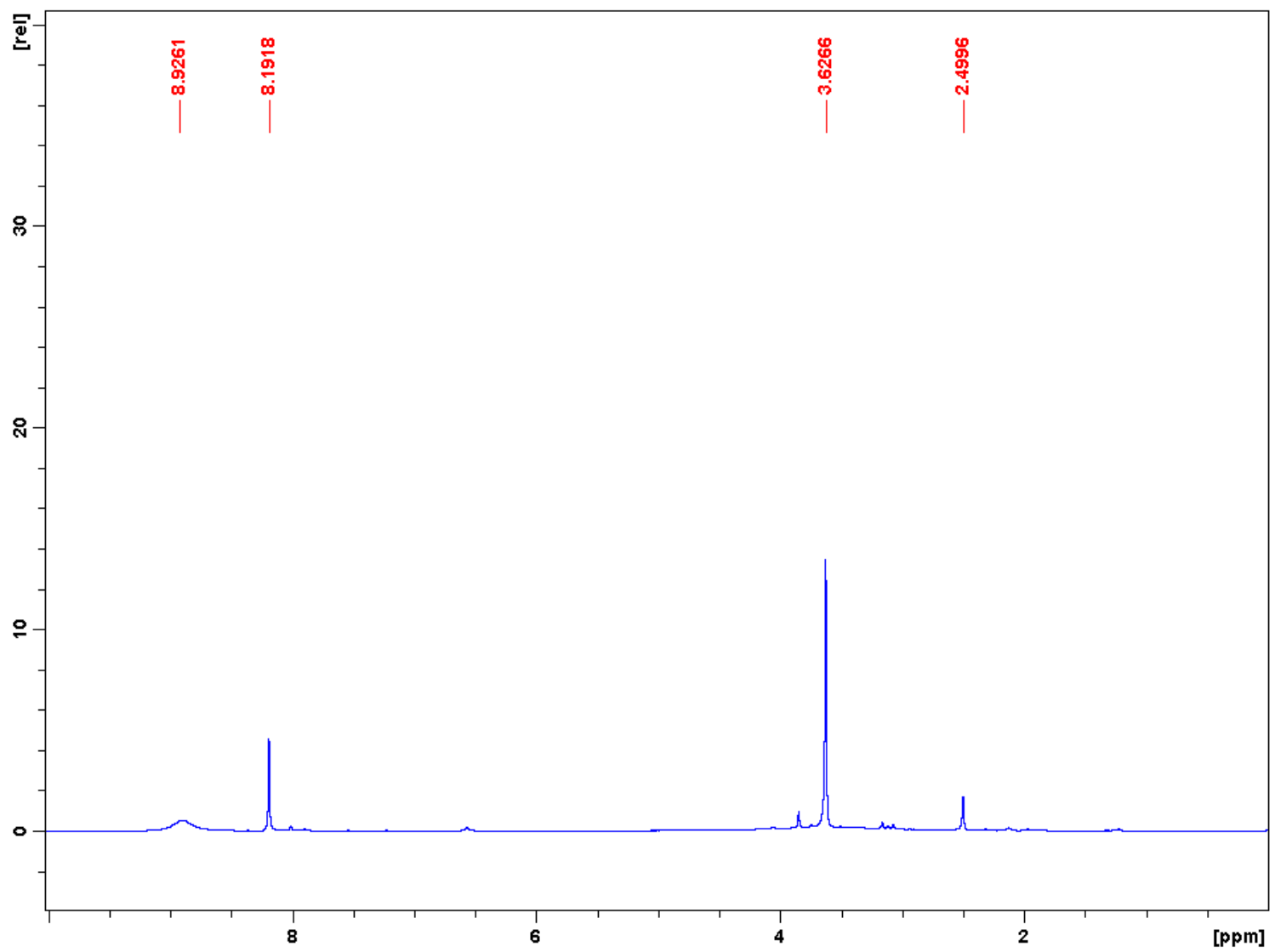

Figure S11. $600 \mathrm{MHz}{ }^{1} \mathrm{H}-\mathrm{NMR}$ spectrum of 8-oxo-9-methyladenine (6) in DMSO- $d_{6}$.

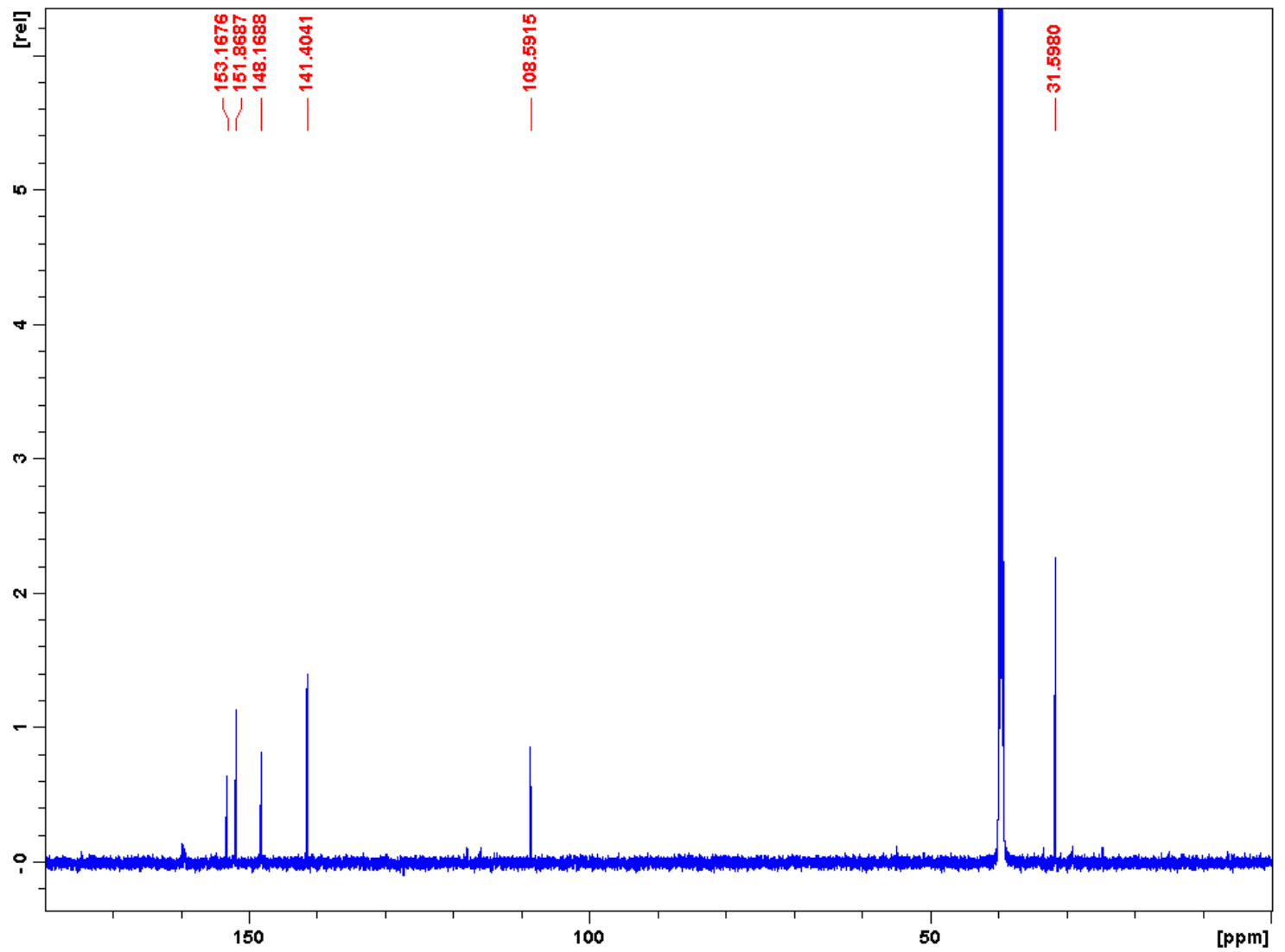

Figure $\mathbf{S 1 2 .} 600 \mathrm{MHz}{ }^{13} \mathrm{C}-\mathrm{NMR}$ spectrum of 8-oxo-9-methyladenine (6) in DMSO- $d_{6}$. 
Table S5. NMR data of 8-oxo-9-methyladenine (6) in DMSO- $d_{6}$.

\begin{tabular}{lllllll}
\hline Pos. & $\delta\left({ }^{1} \mathrm{H}\right)$ & $\delta\left({ }^{13} \mathrm{C}\right)$ & $\delta\left({ }^{15} \mathrm{~N}\right)$ & ${ }^{1} \mathrm{H}^{1}{ }^{1} \mathrm{H}-\operatorname{COSY}$ & ${ }^{1} \mathrm{H}^{13} \mathrm{C}-\mathrm{HMBC}$ & ${ }^{1} \mathrm{H},{ }^{15} \mathrm{~N}-\mathrm{HMBC}$ \\
\hline 1 & - & - & 163 & - & - & - \\
& & & & & & \\
2 & $8.19(1 \mathrm{H}, \mathrm{s})$ & 141.4 & - & - & $4,5,6$ & $1,3,9$ \\
3 & - & - & 235 & - & - & - \\
4 & - & 148.2 & - & - & - & - \\
5 & - & 108.6 & - & - & - & - \\
6 & - & 153.2 & - & - & - & - \\
7 & - & - & n.d. & - & - & - \\
8 & - & 151.9 & - & - & - & - \\
9 & - & - & 109.7 & - & - & - \\
10 & $3.62(3 \mathrm{H}, \mathrm{s})$ & 31.6 & - & - & 4,8 & 9 \\
11 & - & - & n.d. & - & - & - \\
\hline
\end{tabular}<smiles>Cn1c(=O)[nH]c2c(N)ncnc21</smiles>

\section{8-oxo-9-methyladenine}

Figure S13. Atom numbering for 8-oxo-9-methyladenine (6).

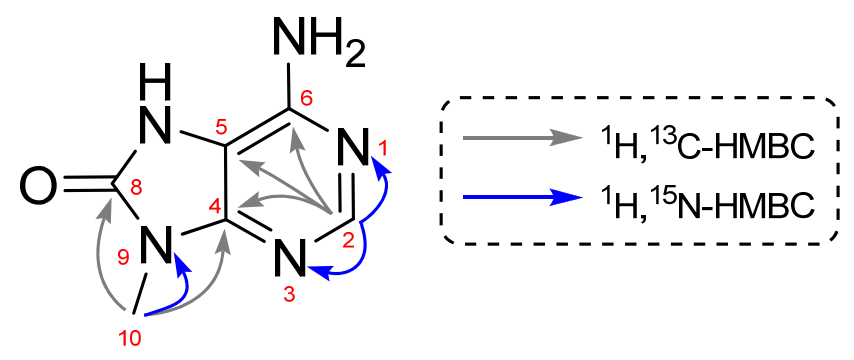

\section{8-oxo-9-methyladenine}

Figure S14. Key ${ }^{1} \mathrm{H},{ }^{13} \mathrm{C}-\mathrm{HMBC}$ (gray arrows) and ${ }^{1} \mathrm{H},{ }^{15} \mathrm{~N}-\mathrm{HMBC}$ (blue arrows) correlations for 8-oxo-9methyladenine (6). 


\section{Results of the bioassays}

Compounds 1-5 were tested against the cancer cell lines L929, KB-31, MCF-7, and FS4-LTM. Unfortunately, the oxoadenine moiety in $15^{\prime}$-oxoadenosceptrin (1) annihilated the bioactivity of sceptrin (3) against KB-31. However, the 2,3'-diamino-3-hydroxy-1'-oxo-propylbenzene in decarboxyagelamadin C (2) allowed a slight enhancement of the bioactivity of oroidin (5) on the same cancer cell lines. Compounds 1 and $\mathbf{2}$ were also tested against Gram-positive [S. aureus (MRSA), S. aureus (MSSA), and M. luteus] and Gram-negative bacteria (P. aeruginosa, $K$. pneumoniae) as well as the fungi C. albicans. Only sceptrin (3) showed a mild MIC (Minimum Inhibitory Concentration) value of $32 \mu \mathrm{M}$ against $M$. luteus and $K$. pneumoniae. Compounds $\mathbf{1}, \mathbf{2}, \mathbf{4}$, and 5 did not show any antibacterial activity.

Table S6. Minimum Inhibitory concentration (MIC) for compounds 1-5 tested against bacteria strains given in $\mu \mathrm{M}$ ("-" means no activity).

\begin{tabular}{|c|c|c|c|c|c|c|}
\hline & \multicolumn{3}{|c|}{ Gram positive } & \multicolumn{2}{|c|}{ Gram negative } & \multirow{2}{*}{$\begin{array}{l}\text { Fungi } \\
\text { C. albicans }\end{array}$} \\
\hline & $\begin{array}{l}\text { S. aureus } \\
\text { (MRSA) }\end{array}$ & $\begin{array}{l}\text { S. aureus } \\
\text { (MSSA) }\end{array}$ & M. luteus & $P$. aeruginosa & K. pneumoniae & \\
\hline 1 & - & - & - & - & - & - \\
\hline 2 & - & - & - & - & - & - \\
\hline 3 & - & - & 32 & - & 32 & - \\
\hline 4 & - & - & - & - & - & - \\
\hline 5 & - & - & - & - & - & - \\
\hline
\end{tabular}

Table S7. Results for compounds 1-5 tested against the cancer cell line L929, KB-31. MCF-7, and FS4LTM (“-“ means no activity).

\begin{tabular}{|c|c|c|c|c|}
\hline & $\begin{array}{l}\mathrm{L} 929[\mu \mathrm{M}] \\
\left(\mathrm{I} \mathrm{C}_{50}, \mathrm{I} \mathrm{I}_{90}\right)\end{array}$ & $\begin{array}{l}\mathrm{KB}-31[\mu \mathrm{M}] \\
\left(\mathrm{IC}_{50}, \mathrm{IC}_{90}\right) \\
\end{array}$ & $\begin{array}{l}\text { MCF-7 }[\mu \mathrm{M}] \\
\left(\mathrm{IC}_{50}, \mathrm{IC}_{90}\right) \\
\end{array}$ & $\begin{array}{l}\text { FS4-LTM }[\mu \mathrm{M}] \\
\left(\mathrm{IC}_{50}, \mathrm{IC}_{90}\right) \\
\end{array}$ \\
\hline 1 & - & - & - & - \\
\hline 2 & - & $44, \geq 130$ & - & - \\
\hline 3 & $193, \geq 238$ & 80,2387 & $238, \geq 238$ & - \\
\hline 4 & - & 29,92 & - & - \\
\hline 5 & - & - & - & - \\
\hline
\end{tabular}


BIOTEST PROCEDURE

\section{Antimicrobial Assays (HZl)}

Determination of antimicrobial activities was carried out by the Helmholtz Center for Infection Research (HZI), and was based on the micro-dilution test, using 96-well micro titration plates. The MIC was defined as 50\% growth inhibition after 24 hour incubation compared to that in the growth control well.

\section{Cytotoxic Assays (HZI)}

The cytotoxicity was determined using WST-1 assays, targeting cell lines L929 mouse fibroblasts, KB31 epidermoid carcinoma, MCF-7 breast cancer, and FS4-LTM conditional immortalization human fibroblasts, respectively. FS4-LTM cell line was incubated for 24 hours with tested substances and the rest cell lines were incubated for 5 days with tested substances. 